\title{
Energy efficiency of buildings and structures in the projection of sustainable competitive advantages of the digital economy
}

\author{
Svetlana Uvarova ${ }^{1}$,Elena Kiseleva ${ }^{1}$, Oksana Papelnyuk ${ }^{2, *}$, and Anetta Gamisonia ${ }^{3}$ \\ ${ }^{1}$ Voronezh State Technical University, Moscow Avenue, 14, Voronezh, 394026, Russia \\ ${ }^{2}$ Moscow State University of Civil Engineering, Yaroslavskoe shosse, 26, Moscow, 129337, Russia \\ ${ }^{3}$ Abkhaz State University, University str., 1, Sukhum, Republic of Abkhazia
}

\begin{abstract}
The paper substantiates the increase in energy efficiency as an imperative to ensure the growth of competitiveness. A conceptual diagram of the relationship between energy efficiency and competitiveness is presented, on the basis of which energy efficiency is postulated as a sustainable competitive advantage of an enterprise or project. At the same time, energy audit and commissioning are substantiated by ways of ensuring sustainable competitive advantages, on the basis of which a procedure for improving the mechanism for ensuring energy efficiency is proposed. In the digital economy, Building Information Modeling (BIM), Building Energy Modeling (BEM), Computational Fluid Dynamics (CFD), and the use of Internet of Things (IoT) technology are postulated as a toolkit for ensuring energy efficiency of investment projects implemented by enterprises.
\end{abstract}

\section{Introduction}

Sustainable development is postulated today as the main priority of the socio-economic development of countries, industries and regions. The basis for sustainable development is high-quality construction products as the basis for creating physical capital to ensure the well-being of future generations. Physical capital, which is buildings and structures of all types, contributes to the implementation of the goals of sustainable economic development due to the optimization of energy efficiency and environmental friendliness, manufacturability and other characteristics of construction products. Accordingly, the level of innovativeness of construction ultimately depends on the well-being of future generations as a target for sustainable development.

The transition to a new technological structure and digitalization of the economy create a new set of conditions for the development of the construction complex. Construction and housing and communal services are, due to their specificity and a number of objective reasons, innovatively passive industries, but today they must not only meet the conditions and criteria for innovation, manufacturability, digitalization, but also slightly outstrip them in order to achieve sustainable development goals.

\footnotetext{
* Corresponding author: oksana-17@mail.ru
} 
The level of compliance with the conditions and criteria of the external environment and the corresponding ability to compete for the possibility of creating objects of physical capital for sustainable development presuppose not only changes in the activity of the enterprise as a subject of the construction complex, but also a change in the construction management paradigm itself, including changes in target focus, performance criteria and methods of economic activity. First of all, a change in the management paradigm will require the formation of a new concept of competitiveness of both the construction industries themselves and the corresponding enterprises and projects.

\section{Materials and Methods}

The analysis of the development of global competition in modern economic conditions [13], carried out by researchers, shows that the subjects of any industry, including construction, are required to accelerate the processes of accepting and processing information, including for the constant introduction of innovations in order to improve consumer properties and value of products for the consumer, and to optimize financial and economic activities, as well as to provide information support in an unstable economic environment. Accordingly, the dyad "competitiveness - innovativeness" stands out, which in the context of the transition to a digital economy should be supplemented with a third element - "digitalization". However, understanding digitalization as innovative changes in the process of exchange and processing of information, it is necessary to consider the relationship between competitiveness and innovation, referring the processes taking place within the framework of digitalization of enterprises and industries to the category of innovation.

The digital economy and the new technological order presuppose the principle of systematic socio-economic development, postulating the development of all construction subjects as systems, and the formation of a corresponding synergistic effect of interaction between the subsystems of the construction complex.

Assessing the elements of competitiveness (product competitiveness, enterprise competitiveness, key competencies) on the basis of established traditional concepts as the results of the functioning of industry or enterprise subsystems, the results of the functioning of the system itself, taking into account the synergistic effect, form precisely systemic competitiveness. Systemic competitiveness, in addition to traditional characteristics, such as a set of actors, their interaction with institutions, the development of competencies, innovation and informatization, includes the effect of synergy from the interaction of all competitive elements and subsystems, due to which its level can exceed the total level of competitiveness of these subsystems.

It is in the digital economy, the system-forming element of which is networkization, that the concept of competitiveness should proceed from the interaction of industry or enterprise subsystems, taking into account the overall target focus of ensuring sustainable development on an innovative basis.

Effective and sustainable economic development is possible only if energy consumption and energy efficiency are optimized both in production and consumption. The result of the increase in energy efficiency is, first of all, an increase in the investment attractiveness of investment and construction projects and facilities. Energy efficiency management leads to a decrease in the total costs of the object's life cycle, which, in turn, leads to an increase in productivity and, ultimately, an increase in competitiveness (fractally within the framework of micro-, meso- and macroeconomics) (Fig. 1). 


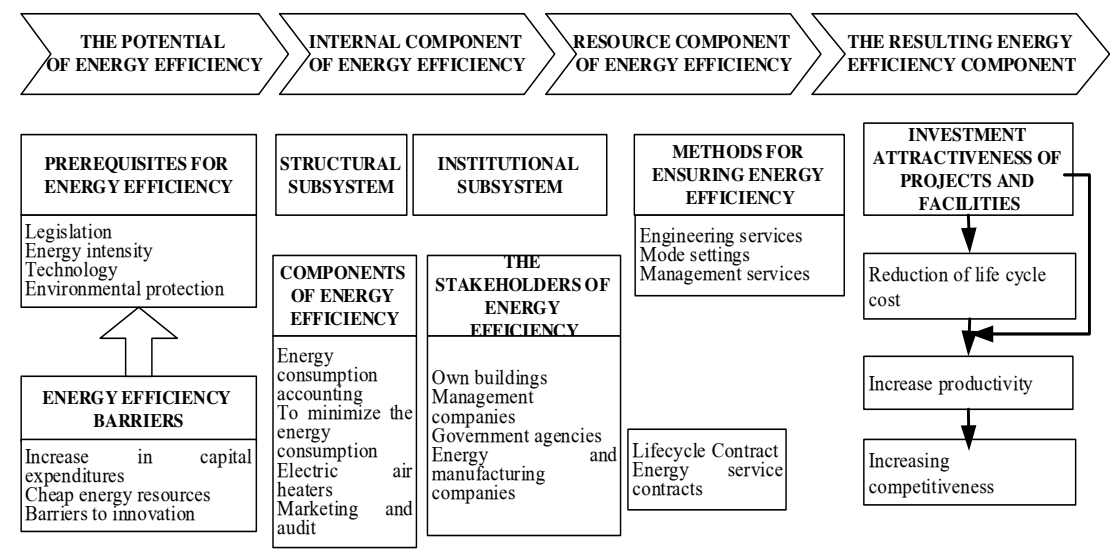

Fig. 1. Conceptual diagram of the relationship between energy efficiency and competitiveness

Based on the presented conceptual scheme, it can be concluded that the end result of realizing the energy efficiency potential in our country will be an increase in competitiveness both at the level of construction projects and, through enterprises and types of economic activities, at the level of regions and the country's economy as a whole. It should be borne in mind that competitiveness in this case represents the implementation of sustainable competitive advantages, which are unique properties of strategic competitiveness in the context of adaptation to constant information and innovative changes in the external environment.

Energy efficiency as a competitive advantage is formed at three stages: resource (due to available energy resources, metering and a certain level of energy consumption), investment (due to the development of energy audit, alternative energy) and innovative (through the implementation of product, process and organizational innovations, including energy modeling, innovation to minimize energy consumption, life cycle contracts and energy service contacts, and so on).

Energy efficiency as a competitive advantage has a long-term or strategic nature, since the need for sustainable economic development and reducing the environmental burden on the environment is growing every year.

In terms of the scale of implementation, energy efficiency as a competitive advantage guarantees both advantages in product production, management and interaction, as well as advantages at the meso and macro levels of the economy.

In terms of coverage, this competitive advantage can be attributed to both external and internal ones. Consequently, with respect to the formation factors, energy efficiency is characterized by a dual relationship: energy efficiency within the framework of the implementation of an investment and construction project leads to a decrease in negative environmental consequences in the external environment, as well as to an increase in the energy efficiency of the regional economy. In turn, the energy efficiency of the economy guarantees the availability of energy efficient solutions at the level of an investment and construction project.

By the nature of the dynamics of the competitive advantage, energy efficiency can be attributed to permanent advantages of a high order, since the introduction of innovations leading to energy efficiency and the use of the potential of energy efficiency in all types of its institutional subsystem guarantees the strategic nature, continuity and uniqueness of this competitive advantage.

Energy efficiency resources create its sustainable competitive advantages, increasing the investment attractiveness of the project and object under construction for all stakeholders 
represented by owners of buildings and structures, management companies, government agencies, as well as energy and industrial enterprises that use energy in their activities.

Realization of sustainable competitive advantages of energy efficiency provides a number of effects.

\section{Results}

Considering the formation of sustainable competitive advantages from the point of view of an informational approach [4], it should be concluded that it is necessary to analyze and process data on the current state of energy consumption of a production, project or building, on the current level of energy consumption and implemented energy-saving measures, on the use of alternative energy sources and the application of energy modeling in the project. An energy audit can become a similar tool or way of forming energy efficiency as a sustainable competitive advantage.

The structure, grounds and results of an energy audit are presented in Figure 2.

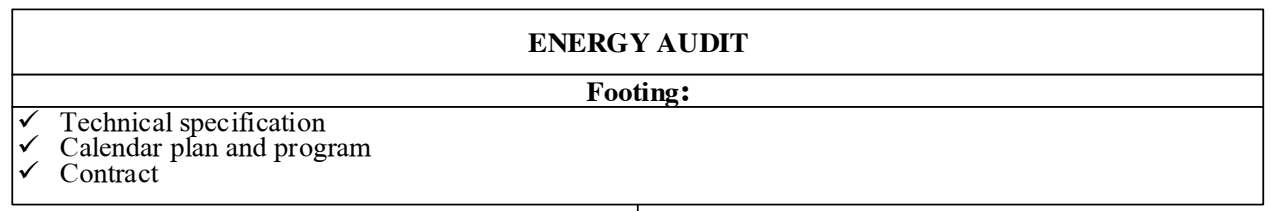

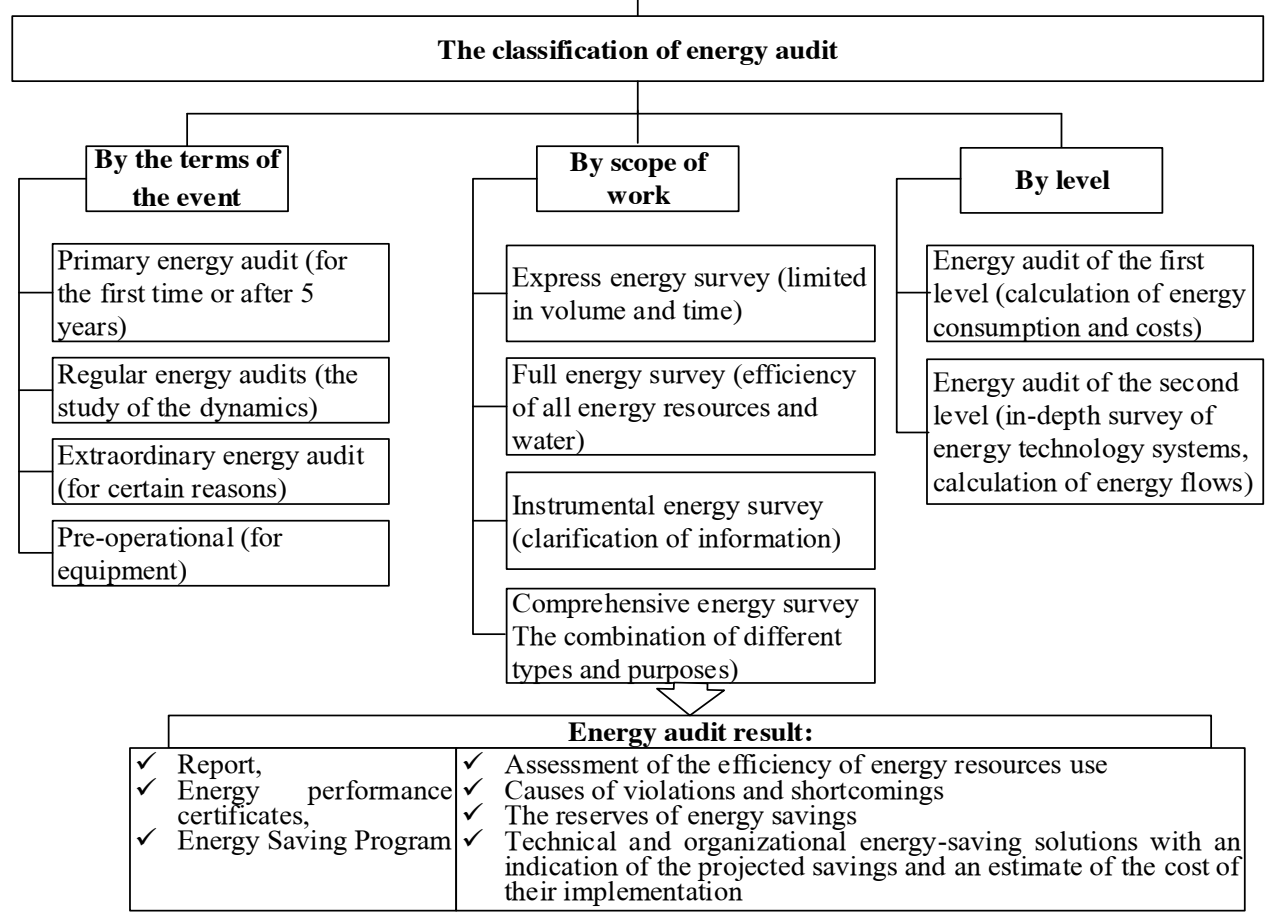

Fig. 2. Energy audit structure, grounds and results

Based on the results of the energy audit, economic indicators of energy efficiency are calculated, including the required amount of capital investments, the dynamics of operating costs, as well as the calculation of the efficiency and return on investment. We consider it expedient to bring the recommendations for energy saving and energy efficiency, developed based on the results of the energy audit, into the "cost-effect" matrix. 
However, despite the efficiency of energy audit as a way to create a sustainable competitive advantage in improving the energy efficiency of a project, building or enterprise, one should take into account a number of institutional problems arising during its implementation, initiation and performance of the issued recommendations, as well as the initiated increase in costs at the construction stage to eliminate deficiencies identified by the energy audit, which, with the availability of relevant information, would be easier and less costly to implement at the design stages or pre-design studies of the project.

In this regard, it seems more expedient to introduce a commissioning tool, similar to the criteria for certification of green building, (Fig. 3).

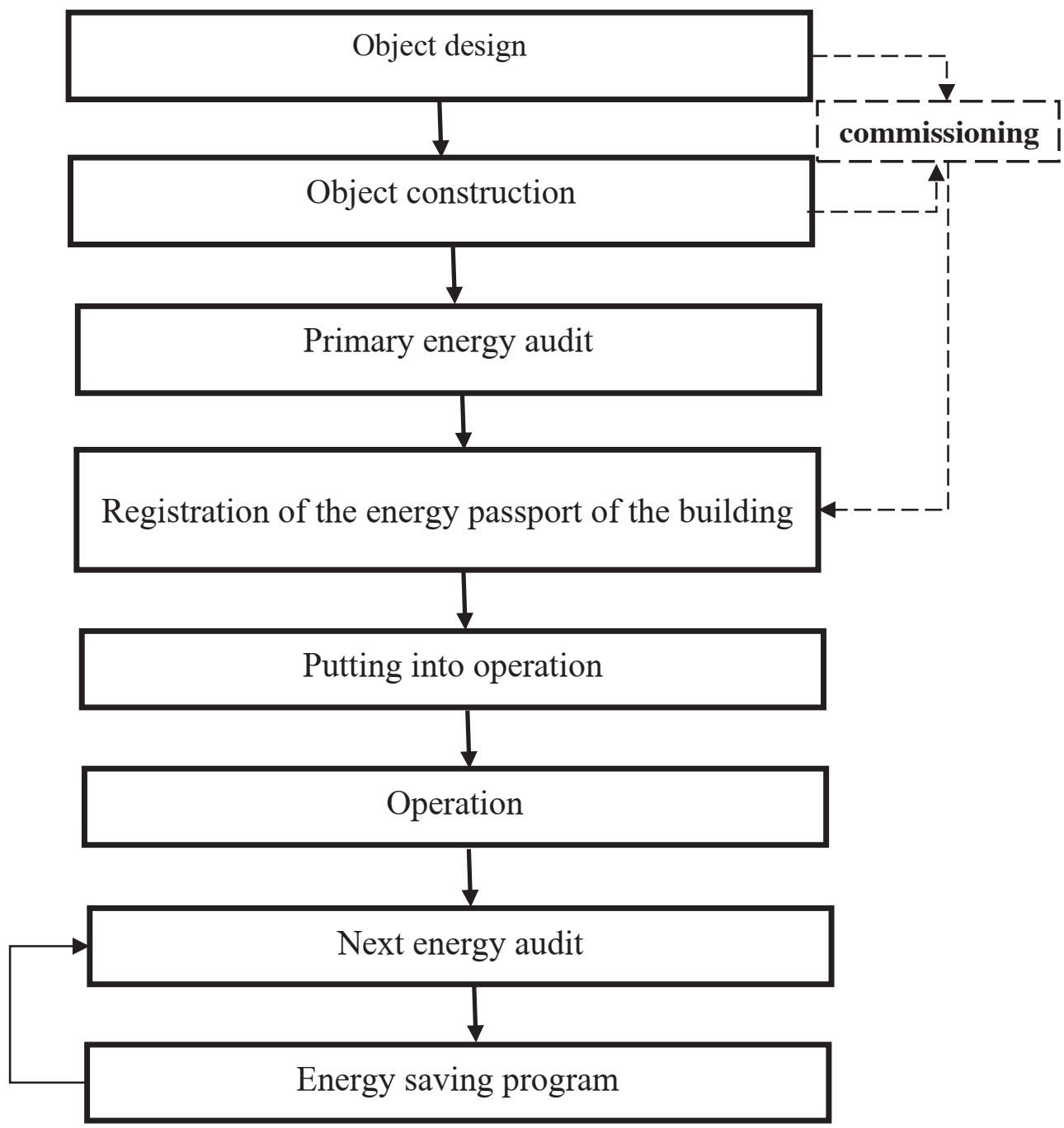

Fig. 3. The procedure for improving the mechanism for ensuring energy efficiency

Commissioning is often associated with the concepts of "putting into operation", "technical audit" or "construction control" [5]. The literal translation of the content of the green standard LEED implies commissioning as consulting services for the commissioning of engineering systems in accordance with the terms of this certification system. It should be noted that, according to the standards, commissioning begins at an early stage of the 
design of the facility and consists in ensuring that the technical requirements of the customer for the facility are taken into account in terms of energy supply, water supply, environmental impact, and its durability at all stages of the life cycle of an investment and construction project. Thus, commissioning functions include construction audit functions, but they have a broader scope, also performing the functions of organizing the process and participating in the development of documentation.

The implementation of the commissioning process creates a guarantee for the sustainability of the competitive advantage of energy efficiency, since it ensures the functioning of the building in accordance with the requirements of the customer or investor, not only by complying with the requirements in the design and construction of the facility, but also by creating an appropriate building management service, ready to maintain the operation of systems and equipment in design mode.

Based on the collection and analysis of information on the existing energy efficiency potential through modeling, conclusions about the areas and methods for improving energy efficiency should be drawn.

In modern conditions of a change in the technological order and the transition to a digital economy, one of the most important energy efficiency resources that allow creating a sustainable competitive advantage from the position of an information approach is the use of digital technologies for the design, construction and operation of facilities in order to increase their energy efficiency. The digitalization of construction is based on information modeling technology, but BIM does not contain modules for solving issues of the energy efficiency of a building, since the information model does not contain information about energy processes taking place inside and outside the building.

Assessment and modeling of the energy processes of the designed object is possible by applying the technology of Building Energy Modeling and Computational Fluid Dynamics (BEM and CFD) [6].

Building Energy Modeling (BEM) technology allows assessing the energy efficiency of a building during operation, identify energy bottlenecks and optimize the corresponding processes. Nowadays, the use of BEM is the most accurate engineering tool that allows supporting decision-making, leading to a decrease in the time and cost of a construction investment project and a decrease in the operational cost of an object.

Computational Fluid Dynamics (CFD) makes it possible to create models of heat and mass transfer processes in the air of the designed object with a minimum error. Nowadays, this is the only method that allows determining the effectiveness of the designed solutions with the reliability almost equal to the full-scale experiment. The effect of using the CFD model is to save time and money on the substantiation and confirmation of technical solutions. The possibility of acceptance and assessment by the state examination bodies of the results of CFD-modeling is important.

As a rule, a BIM model contains an amount of information that is redundant for CFD/BEM, since only object surfaces that affect heat transfer are taken into account in energy modeling, and in CFD - model components that affect air flow. The main data for energy modeling is information about weather dynamics, parameters of building systems, as well as the model of the proposed equipment. The main input data of CFD are the parameters of the building environment and external environment, air flow characteristics and other data. Based on the above data, appropriate calculations are performed. If necessary, the model is adjusted, and new parameters are calculated. The use of BIM reduces the time and costs for preparing a computational energy modeling model by almost $90 \%$.

At the stage of construction and operation of the facility, the Internet of Things (IoT) technologies are used as key digital technologies, which allow automated analysis in real time and generating reports on key indicators of energy efficiency, energy consumption and 
equipment maintenance management. Also, on the basis of data received in real time from IoT devices when they are processed by appropriate information analysis technologies, including artificial intelligence, recommendations are made to improve approaches to energy management to ensure the achievement of energy efficiency targets.

The volumes, platforms and methods of information modeling, as well as the scale and sequence of digitalization of measures to improve the energy efficiency of facilities as the creation of sustainable competitive advantages should be determined by calculation when comparing costs and effects, including non-financial ones.

\section{Discussions}

Organizational innovations based on the use of digital technologies contribute to improving energy efficiency at all stages of the object's life cycle by initially assessing the impact of future factors and choosing the best equipment, as well as by continuously monitoring subsystems and optimizing management and maintenance systems of the facility to further improve energy efficiency and reduce operating costs.

The formation of sustainable competitive advantages in construction is possible in two main areas: the implementation of innovative projects (the introduction of innovations in the implementation of investment projects) and digitalization. It should be noted that the implementation of the UCO at the level of projects and enterprises contributes to the growth of the level of competitiveness only in the case of a complete and accurate substantiation and calculation of their efficiency. Moreover, in modern conditions, the efficiency of the UCO should take into account both the size of the monetized effect and the influence of non-financial types of effect, including on related enterprises and industries that are in network interaction [7-9].

The successful implementation of the UCO contributes to the growth of the competitiveness of construction, which today is a primary task at the meso-level of management due to the low competitiveness rating of the industry, especially taking into account the level of its digitalization.

\section{Conclusion}

The implementation of the UCO is essentially an innovative project characterized by indicators of feasibility, efficiency, and sustainability of the competitive advantages being formed. The successful implementation of a pool of projects contributes to ensuring the systemic competitiveness of the enterprise. The results of the functioning of the industry as a whole should characterize the results of the activities of its constituent enterprises. Moreover, the criteria for the effective functioning of the industry should assess the efficiency of the implementation of UCO by enterprises and organizations, taking into account the synergy of all types of competitive advantages.

The development of construction based on a combination of proactive management through the formation of innovative trends in the external and internal environment in the strategic horizon and adaptive management through the implementation of innovations in the operational horizon can provide a strategic focus and an upward trend of competitiveness in the face of constant environmental transformations.

\section{References}

1. S. Belyaeva, D. Voronov, S. Erypalov, MATEC Web of Conferences, 106, 08033 (2017) 
2. E. Nezhnikova, O. Papelnyuk, M. Dudin, International Journal of Energy Economics and Policy 9, 172-178 (2019)

3. M. Tetik, A. Peltokorpi, O. Seppänen, J. Holmström, Automation in Construction, 107, Article 102910 (2019)

4. K. E. Kovalenko, S. Y. Bakhvalov, A. O. Zekiy, V. V. Vikulina, S. A. Tinkov, T. V. Tkacheva, Key indicators of innovation activity of Russia (from 2011 to 2017). Journal of Entrepreneurship Education, 22(3), 1-7 (2019)

5. O. V. Konina, S. A. Tinkov, E. V. Tinkova, Management in Higher Education Based on "Smart Technologies": Digital Managerial Staff vs. Artificial Intelligence. Lecture Notes in Networks and Systems, 155, 1738-1745 (2021)

6. S. S. Uvarova, Kh. Gumba, E. Kiseleva, Ya. Sonin, E3S Web of Conferences. XIII International Scientific and Practical Conference "State and Prospects for the Development of Agribusiness - INTERAGROMASH 2020", 11004 (2020)

7. A. Kogan. Journal of Advanced Research in Law and Economics 1(11), 112 - 120 (2015)

8. I. Ilin, V. Vasilenok, R. Marchenko, Use of renewable energy and tax burden on CO2 emissions in industrial enterprises, E3S Web of Conferences, 110, 0210 (2019)

9. A. Poljanskihh, A. Levina, A. Dubgorn, Investment in renewable energy: Practical case in Estonia, MATEC Web of Conferences, 193, 05065 (2018) 